Article

\title{
Effect of Sweet Corn Residue on Micronutrient Fortification in Baked Cakes
}

\author{
Yu-Xia Lao ${ }^{1}$, Yu-Ying Yu ${ }^{1}$, Gao-Ke Li ${ }^{2}$, Shao-Yun Chen ${ }^{1}$, Wu Li ${ }^{2}$, Xu-Pu Xing ${ }^{1}$, Xue-Min Wang ${ }^{1}$, \\ Jian-Guang $\mathrm{Hu}^{2, *}$ and Xin-Bo Guo ${ }^{1, * \mathbb{D}}$ \\ 1 School of Food Science and Engineering, South China University of Technology, Guangzhou 510640, China \\ 2 Key Laboratory of Crops Genetics Improvement of Guangdong Province, Crop Research Institute, \\ Guangdong Academy of Agricultural Sciences, Guangzhou 510640, China \\ * Correspondence: jghu2003@263.net (J.-G.H.); guoxinbo@scut.edu.cn (X.-B.G.)
}

Received: 28 May 2019; Accepted: 11 July 2019; Published: 16 July 2019

\begin{abstract}
Owing to the concept of modern life and health, traditional baked foods are seeking transition. In this study, sweet corn residue (SCR) was used to replace wheat flour in cakes. We conducted sensory evaluation and texture analysis to assess sample quality. Also, we simulated digestion in vitro, and determined the content of total sugar and dietary fiber. The content of vitamin E and carotenoids were determined by High Performance Liquid Chromatography (HPLC), and the content of folate was determined by a microbiological method. With the increase of SCR, the content of dietary fiber, folate, vitamin $\mathrm{E}$, and carotenoids significantly increased, and the digestive characteristics improved simultaneously. Based on the above evaluations, SCRC2 (sweet corn residue cake with $60 \%$ substitution) had similar sensory quality to the control (pure wheat flour cake) and had the characteristics of slow digestibility and high micronutrients.
\end{abstract}

Keywords: sweet corn; cake; vitamin E; carotenoids; folate

\section{Introduction}

Traditional baked foods, being rich in fat and sugar, are not in line with modern people's pursuit of health. Besides, excessive energy intake makes people prone to chronic diseases such as obesity [1]. Studies have illustrated that increased crude food consumption is associated with reduced risk of cardiovascular disease, type 2 diabetes, and some cancers [2,3]. Meanwhile, whole grains provide various healthy phytochemicals (including phenolics, carotenoids, and vitamin E) and dietary fiber.

People improved the whole grain content of baked food by adding different ways to obtain healthier delicacies. Gómez et al. [4] made cakes with wheat, rye, barley, and other whole wheat flours to reduce the risk of diabetes. Žilić et al. [5] added anthocyanin-rich corn flour to cookies to improve their antioxidant activity. Omoba et al. [6] developed whole grain sorghum-soya and pearl millet-soya composite biscuits as dietary fiber supplements. Others increased daily intake of lutein and whole grain foods by processing baked food containing high lutein and lutein-fortified whole wheat flour [7].

Sweet corn is a common cereal, with access to phytochemicals such as dietary fiber, vitamin E, carotenoids, and folate. Sweet corn residue (SCR), a byproduct of sweet corn juice extrusion, has similar characteristics. The dietary fiber in SCR is neither digested nor absorbed, and adequate intake contributes to reduce blood sugar and prevent colorectal cancer [8]. Vitamin E is a lipid-soluble vitamin, which is conducive to reducing cardiovascular risk, immune regulation, and is anti-allergy [9]. Carotenoids have good biological activity. Adequate intake of carotenoids can reduce the risk of breast cancer, and cardiovascular and eye diseases $[10,11]$. Folate is essential for human metabolism. Low folate can lead to various adverse reactions and diseases, for instance, inadequate folate intake in early pregnancy can easily cause fetal neural tube defects and malformation [12,13]. 
In our study, SCR was used to replace wheat flour to make cakes. The sensory evaluation, texture characteristics, and digestive characteristics of sweet corn residue cake (SCRC) with different additions were compared. The composition and content of dietary fiber, vitamin E, carotenoids, and folate in cakes were determined. The purpose of our study was to increase the added value of SCR and develop a cake with slow digestibility and high nutrition for consumers concurrently.

\section{Materials and Methods}

\subsection{SCR Preparation}

The variety YT28 of fresh sweet corn kernels was obtained from the Crop Science Institute of Guangdong Academy of Agricultural Sciences (Guangzhou, China). We dried the residue obtained from the squeezing of sweet corn kernels, crushed it into powder by a pulverizer (Yongkang Zhaoshen Electrical Appliances Co., Ltd., Yongkang, China), then sifted it through 40 meshes. The SCR was packed and sealed for using.

\subsection{Cake Formulation and Preparation}

SCR was prepared in our laboratory, meanwhile, other raw materials were purchased from local supermarkets. Corresponding improvements have been made to the method of Xian et al. [14], and we made batter in the light of the formula in Table 1 and baked it. The baked cakes were cooled and sealed for further inspection.

Table 1. Formulation of sweet corn residue (SCR) cakes.

\begin{tabular}{cccccc}
\hline Ingredients (g) & Control & SCRC1 & SCRC2 & SCRC3 & SCRC4 \\
\hline SCR & 0 & 15 & 30 & 45 & 50 \\
Low-gluten flour & 40 & 28 & 16 & 4 & 0 \\
High-gluten flour & 10 & 7 & 4 & 1 & 0 \\
Egg & 95 & 95 & 95 & 95 & 95 \\
Sugar & 36 & 36 & 36 & 36 & 36 \\
Salt & 0.3 & 0.3 & 0.3 & 0.3 & 0.3 \\
Soybean lecithin & 0.5 & 0.5 & 0.5 & 0.5 & 0.5 \\
Baking powder & 2.5 & 2.5 & 2.5 & 2.5 & 2.5 \\
Corn oil & 25 & 25 & 25 & 25 & 25 \\
Milk & 60 & 65 & 65 & 70 & 70 \\
\hline
\end{tabular}

All the samples were numbered according to composition. The pure wheat flour was the control, and SCR with $30 \%, 60 \%, 90 \%$, and $100 \%$ substitution was named SCRC1, SCRC2, SCRC3, and SCRC4.

\subsection{Sensory Evaluation}

Modified in ISO 8587:2006 [15] and ISO 5495:2005 [16], sensory evaluation was organized. We established the evaluation criteria of color, texture, shape, taste, and flavor by the predicted results. The full score of each index was 20 points; a higher score represented closer to the standard. In the sensory evaluation laboratory, we presented 5 numbered cake samples to 12 trained tasters. They completed the evaluation independently and recorded results. Data were reported as mean \pm SD $(n=12)$.

\subsection{Texture Profile Analysis of Cakes}

Modifying Brites et al. [17], texture characteristics of cakes were measured with a texture analyzer (TA.XTplusC Texture Analyser, Stable Micro Systems, London, UK), and cubes of $20 \mathrm{~mm}$ cake cores were used as the test samples. Texture profile analysis (TPA) was performed at a pretest speed of $2 \mathrm{~mm} \cdot \mathrm{s}^{-1}$, test speed of $1 \mathrm{~mm} \cdot \mathrm{s}^{-1}$, time interval of $5 \mathrm{~s}$, and strain deformation of $50 \%$ by an aluminum 
probe $\mathrm{P} / 25 \mathrm{R}$. Hardness, resilience, cohesion, springiness, gumminess, and chewiness were calculated from the TPA graphic. Data were reported as mean $\pm \mathrm{SD}(n=3)$.

\subsection{Determination of Total Sugar}

The total sugar content of the samples was determined by the anthrone-sulfate method [18]. Anhydrous glucose was used as standard material and drew a standard curve. We crushed and dissolved samples and took the supernatant after centrifugation. The reaction liquid was obtained by a reaction of diluted supernatant with anthrone. The absorbance value was determined by visible-ultraviolet spectrophotometer at $620 \mathrm{~nm}$. The total sugar content was expressed in $\mathrm{mg} / 100 \mathrm{~g}$ sample (mean $\pm \mathrm{SD}, n=3$ ).

\subsection{Determination of Dietary Fiber}

Modifying Kamotho et al. [19], dietary fiber was determined by an SLQ-6 semi-automatic fiber analyzer (Shanghai Fiber Inspection Instrument Co., Ltd., Shanghai, China). We added samples, then preheated the acid-based solution and ultrapure water. We stopped the reaction after digesting for $35 \mathrm{~min}$ and washed the residue. We dried and weighed the remaining solids and then calculated the content.

\subsection{In Vitro Digestion}

Modifying Gao et al. [20,21], we made corresponding improvements. Referring to white bread (Blank), we used pepsinase, alpha-amylase, and buffer to simulate digestion in vitro. The digestive samples were taken at $0,15,60,90,120,150$, and $180 \mathrm{~min}$ respectively. We deactivated the enzymes and then diluted them. The content of reducing sugar was determined by 3,5-Dinitrosalicylic acid (DNS), and the absorbance at $540 \mathrm{~nm}$ was measured by the enzyme label. The results were expressed as mean $\pm \mathrm{SD}(n=3)$.

\subsection{Extraction and Determination of Vitamin $E$}

Vitamin E in cake samples was extracted and determined referring to Xie et al. [22,23]. For the saponified cake samples, we extracted a mixture with n-hexane/ethyl acetate $(9: 1 \mathrm{v} / \mathrm{v})$ and then collected an organic layer. After evaporation, the residues were dissolved in isopropanol (1\%) n-hexane solution for HPLC. Equipped with a Waters 2475Multi $\lambda$ Fluorescence Detector and Waters 515 HPLC pump, an NP-HPLC system was chosen for vitamin E determination. Additionally, an Agilent ZORBAX RX-SIL column was used. By the comparison of retention time between samples and standards, the identification of vitamin $\mathrm{E}$ was carried out. The results were reported as $\mu \mathrm{g} / 100 \mathrm{~g}$ sample (mean \pm $\mathrm{SD}, n=3)$.

\subsection{Extraction and Determination of Carotenoids}

Consulting Liu et al. [24], the extraction and determination of carotenoids in SCRC was performed. In this experiment, the extraction of carotenoids was the same as vitamin E. Separation and quantification were performed by a HPLC system (Waters Corporation, Milford, MA, USA), with YMCTM carotenoid $30,4.5 \times 250 \mathrm{~mm}$ column, and a photodiode array detector. Comparing the storage time of standard carotenoid samples, the content of carotenoid was determined. The results were reported as $\mu \mathrm{g} / 100 \mathrm{~g}$ sample (mean $\pm \mathrm{SD}, n=3$ ).

\subsection{Extraction and Determination of Folate}

Modifying Shan et al. $[23,25]$, the extraction and determination of folate in cakes was conducted. We crushed samples to extract folate, then determined the content. Briefly, the extracts and Difco ${ }^{\mathrm{TM}}$ Folic Acid Assay Medium (Sparks, MD, USA) was mixed. Additionally, for inoculation, an Enterococcus hirae (ATCC ${ }^{\circledR} 8043^{\mathrm{TM}}$, American Type Culture Collection, Manassas, VA, USA) suspension was used. 
The content of folate was calculated according to folic acid standard curves (Sigma, St. Louis, MO, USA) after absorbance values were measured at $660 \mathrm{~nm}$. The results of folate content were shown as $\mu \mathrm{g} / 100 \mathrm{~g}($ mean $\pm \mathrm{SD}, n=3)$.

\subsection{Statistical Analysis}

In this study, statistical analysis was conducted by the Origin Lab Corporation (Northampton, MA, USA). With SPSS software 21.0 (SPSS, Chicago, IL, USA), we analyzed the differences among samples by Tukey's multiple comparison test $(p<0.05)$, the correlation between SCR addition, and evaluation results by Pearson coefficient as well.

\section{Results}

\subsection{Effect of SCR on Sensory Quality of Cake}

Table 2 reported the results of evaluation of color, texture, shape, taste, and flavor. In Table 2, we observed that there was no significant difference among SCRC1, SCRC2, and the control. The texture and shape of SCRC1 and SCRC2 were slightly inferior to that of the control. However, they had more uniform color and a rich sweet corn flavor. SCRC3 was similar to SCRC4, but abundant SCR caused a sag in the shape and a dark color. Consequently, their scores decreased significantly. Generally speaking, when the SCR content was less than $60 \%$, the negative effect of its substitution on cake quality could be neglected. Instead, consumers preferred the natural corn fragrance it brought.

Table 2. Effect of SCR addition on the sensory quality of cakes. The five indicators (color, texture, shape, taste, flavor) have the same proportions.

\begin{tabular}{ccccccc}
\hline Products & Color & Texture & Shape & Taste & Flavor & Total Score \\
\hline Control & $14.18 \pm 2.36$ & $17.55 \pm 2.11$ & $16.64 \pm 1.96$ & $18.00 \pm 1.61$ & $14.64 \pm 3.53$ & $81.00 \pm 7.81$ \\
SCRC1 & $15.82 \pm 1.72$ & $16.00 \pm 2.00$ & $16.00 \pm 2.28$ & $16.00 \pm 3.29$ & $16.27 \pm 2.65$ & $80.09 \pm 8.61$ \\
SCRC2 & $15.36 \pm 2.94$ & $15.73 \pm 2.69$ & $15.82 \pm 2.56$ & $15.36 \pm 2.94$ & $17.18 \pm 2.14$ & $79.45 \pm 10.93$ \\
SCRC3 & $14.55 \pm 3.50$ & $14.09 \pm 2.91$ & $13.82 \pm 3.34$ & $12.55 \pm 4.27$ & $15.27 \pm 2.971$ & $70.27 \pm 14.46$ \\
SCRC4 & $14.45 \pm 5.16$ & $13.82 \pm 3.37$ & $14.09 \pm 4.30$ & $12.09 \pm 3.51$ & $15.00 \pm 3.46$ & $69.45 \pm 15.45$ \\
\hline
\end{tabular}

\subsection{Effect of SCR on Texture Characteristics of Cake}

The test results with the texture analyzer (TA.XTplusC Texture Analyser, Stable Micro Systems, London, UK)are shown in Table 3. Observation of Table 3 showed that when the SCR content was less than $60 \%$, the hardness and chewiness of the cake decreased, and the gumminess became poor, but the springiness and cohesion changed slightly, or even improved. When the SCR content reached $90 \%$ or $100 \%$, the cake became harder and more difficult to chew. Its springiness and resilience decreased significantly, and the overall quality of the cake deteriorated.

Table 3. Effect of Sweet corn residue (SCR) addition on the texture characteristics of cakes.

\begin{tabular}{ccccccc}
\hline Products & $\begin{array}{c}\text { Hardness } \\
(\mathbf{g})\end{array}$ & $\begin{array}{c}\text { Resilience } \\
\mathbf{( \% )}\end{array}$ & Cohesion & $\begin{array}{c}\text { Springiness } \\
\mathbf{( \% )}\end{array}$ & $\begin{array}{c}\text { Gumminess } \\
(\mathbf{g})\end{array}$ & $\begin{array}{c}\text { Chewiness } \\
(\mathbf{g})\end{array}$ \\
\hline Control & $269.6 \pm 14.2 \mathrm{~b}$ & $28.00 \pm 1.17 \mathrm{c}$ & $0.7245 \pm 0.016 \mathrm{bc}$ & $78.86 \pm 3.76 \mathrm{ab}$ & $195.8 \pm 8.3 \mathrm{bc}$ & $153.0 \pm 6.6 \mathrm{bc}$ \\
SCRC1 & $195.1 \pm 7.1 \mathrm{a}$ & $30.93 \pm 0.45 \mathrm{~d}$ & $0.7497 \pm 0.0178 \mathrm{c}$ & $84.76 \pm 6.70 \mathrm{~b}$ & $144.8 \pm 5.3 \mathrm{a}$ & $123.3 \pm 11.5 \mathrm{a}$ \\
SCRC2 & $259.9 \pm 12.2 \mathrm{~b}$ & $27.50 \pm 0.93 \mathrm{c}$ & $0.7122 \pm 0.0154 \mathrm{~b}$ & $75.41 \pm 1.98 \mathrm{a}$ & $183.4 \pm 8.0 \mathrm{~b}$ & $135.5 \pm 10.4 \mathrm{ab}$ \\
SCRC3 & $310.8 \pm 26.1 \mathrm{c}$ & $24.54 \pm 0.44 \mathrm{~b}$ & $0.6741 \pm 0.0053 \mathrm{a}$ & $76.08 \pm 0.40 \mathrm{a}$ & $201.0 \pm 16.7 \mathrm{c}$ & $159.6 \pm 11.9 \mathrm{c}$ \\
SCRC4 & $388.8 \pm 20.0 \mathrm{~d}$ & $22.01 \pm 0.80 \mathrm{a}$ & $0.6598 \pm 0.0083 \mathrm{a}$ & $73.81 \pm 0.52 \mathrm{a}$ & $256.9 \pm 9.4 \mathrm{~d}$ & $188.2 \pm 9.0 \mathrm{~d}$ \\
\hline
\end{tabular}

Means in the same column with different letters are significantly different $(p<0.05)$. 


\subsection{Dietary Fiber in Cakes}

The results were $3.67 \%$ and $1.75 \%$, respectively. In our study, the baking temperature was far below the requirement of dietary fiber decomposition. Thus, we speculated that the loss of dietary fiber in SCR during the cake making process could be negligible, and the fiber content in cake products could be converted by raw materials. Converted, the content of dietary fiber in the control, SCRC1, SCRC2, SCRC3, and SCRC4 were 324.6, 423.5, 528.3, 621.,7 and $656.1 \mathrm{mg} / 100 \mathrm{~g}$, respectively.

\subsection{In Vitro Digestion of Cakes}

Figure 1 reflected the amount of reducing sugar released in $180 \mathrm{~min}$, which was obtained from starch hydrolyzed by digestive enzymes. From Figure 1, the reducing sugar of all samples was released rapidly in the first $20 \mathrm{~min}$, but the content of reducing sugar released during subsequent digestion was strikingly different. When digestion in vitro stopped, the AUC (area under the curve, which meant total release of reduced sugar during $180 \mathrm{~min}$ of in vitro digestion) of the control, SCRC1, SCRC2, SCRC3, and SCRC4 only accounted for $80 \%, 56 \%, 41 \%, 8.7 \%$, and $6.9 \%$ of Blank. Thus, we inferred that the Glycemic Index (GI) value of cake samples decreased significantly with the increase of SCR. Simultaneously, the content of soluble reducing sugar in the control, SCRC1, SCRC2, SRC3, SCRC4, and Blank were $69.9,64.3,48.5,40.4,29.9$, and $105.6 \mathrm{mg} / \mathrm{g}$, respectively. One gram of soluble reducing sugar provided about $16 \mathrm{~kJ}$ of calories. It could be inferred that the calories provided by reducing sugar in $100 \mathrm{~g}$ samples were 1118.4, 1028.8, 776.0, 646.4, 478.4, and $1689.6 \mathrm{~kJ}$, sequentially. However, the total sugar content determined by the anthrone method was inconsistent with the results of in vitro digestion, as shown in Table 4.

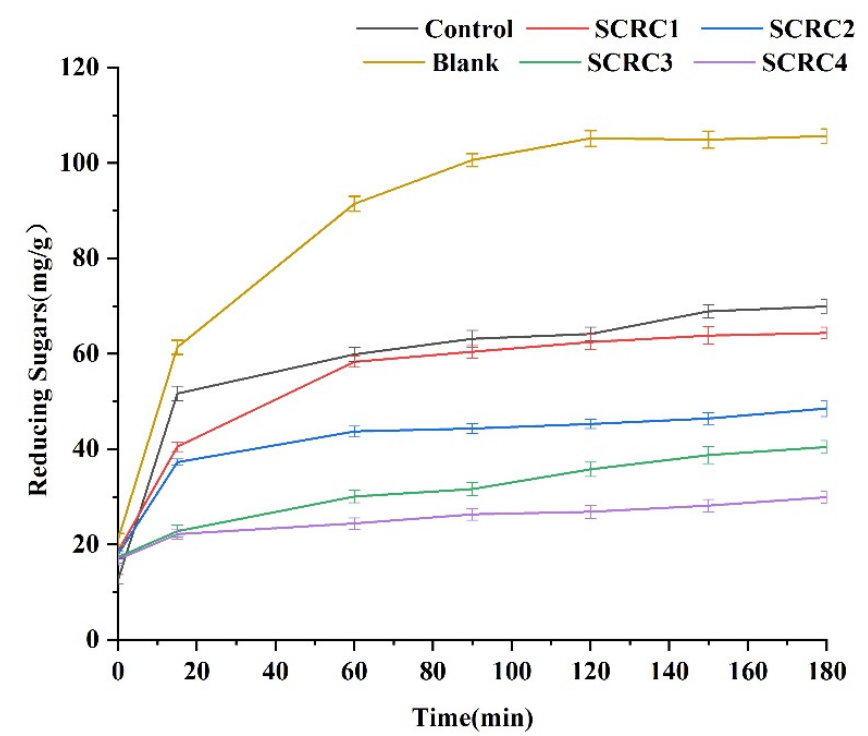

Figure 1. Amount of reducing sugars released from Sweet corn residue (SCR) cakes during in vitro digestion.

Table 4. Effect of SCR on total sugar and in vitro digestion profile in samples.

\begin{tabular}{ccc}
\hline Products & Total Sugar $(\mathbf{m g} / \mathbf{g})$ & AUC (Area under the Curve) \\
\hline Control & $158.9 \pm 9.1 \mathrm{c}$ & $4133 \pm 54 \mathrm{e}$ \\
SCRC1 & $169.2 \pm 1.9 \mathrm{~d}$ & $2895 \pm 50 \mathrm{~d}$ \\
SCRC2 & $135.6 \pm 3.6 \mathrm{~b}$ & $2115 \pm 10 \mathrm{c}$ \\
SCRC3 & $165.0 \pm 5.5 \mathrm{~cd}$ & $454.9 \pm 16.5 \mathrm{~b}$ \\
SCRC4 & $168.2 \pm 1.9 \mathrm{~d}$ & $359.5 \pm 17.5 \mathrm{a}$ \\
Blank & $112.5 \pm 0.4 \mathrm{a}$ & $5212 \pm 35 \mathrm{f}$ \\
\hline
\end{tabular}

Means in the same column with different letters are significantly different $(p<0.05)$. 


\subsection{Composition and Content of Vitamin E in Cakes}

The composition and content of vitamin E detected in cakes are indicated in Table 5. $\alpha_{-}^{-}, \beta-, \gamma^{-}$, $\delta$-tocopherols and $\alpha-, \beta-, \gamma^{-}, \delta$-tocotrienols were detected in this study. The content of $\gamma$-tocopherol was the highest - about half of the total-followed by $\alpha$-tocopherol, and $\delta$-tocotrienol was the lowest. The cakes in our study all contained high vitamin E content owing to the use of corn oil. The result indicated that the vitamin E content of SCRC was about 1.5 times that of the control. In other words, the addition of SCR could significantly increase the vitamin E content of cake.

Table 5. Composition and content $(\mu \mathrm{g} / 100 \mathrm{~g})$ of vitamin $\mathrm{E}$ in cakes.

\begin{tabular}{cccccc}
\hline Compositions & Control & SCRC1 & SCRC2 & SCRC3 & SCRC4 \\
\hline$\alpha-\mathrm{T}$ & $615.4 \pm 13.8 \mathrm{a}$ & $1022 \pm 1 \mathrm{~b}$ & $937.0 \pm 33.7 \mathrm{~b}$ & $946.4 \pm 53.9 \mathrm{~b}$ & $989.1 \pm 52.3 \mathrm{~b}$ \\
$\alpha-\mathrm{T} 3$ & $73.34 \pm 3.61 \mathrm{a}$ & $146.2 \pm 0.2 \mathrm{~b}$ & $193.3 \pm 3.4 \mathrm{c}$ & $221.0 \pm 10.5 \mathrm{~d}$ & $232.0 \pm 12.4 \mathrm{~d}$ \\
$\beta-\mathrm{T}$ & $39.56 \pm 0.04 \mathrm{a}$ & $48.24 \pm 0.63 \mathrm{~b}$ & $42.21 \pm 2.30 \mathrm{a}$ & $39.31 \pm 1.91 \mathrm{a}$ & $42.12 \pm 1.57 \mathrm{a}$ \\
$\gamma-\mathrm{T}$ & $1056 \pm 12 \mathrm{a}$ & $1367 \pm 1 \mathrm{~d}$ & $1142 \pm 26 \mathrm{~b}$ & $1168 \pm 36 \mathrm{~b}$ & $1251 \pm 39 \mathrm{c}$ \\
$\gamma-\mathrm{T} 3$ & $127.0 \pm 8.5 \mathrm{a}$ & $245.8 \pm 1.1 \mathrm{~b}$ & $318.4 \pm 0.9 \mathrm{c}$ & $381.8 \pm 16.6 \mathrm{~d}$ & $393.8 \pm 17.9 \mathrm{~d}$ \\
$\delta-\mathrm{T}$ & $47.27 \pm 0.84 \mathrm{c}$ & $51.05 \pm 0.62 \mathrm{~d}$ & $39.96 \pm 0.35 \mathrm{a}$ & $42.02 \pm 1.34 \mathrm{~b}$ & $48.67 \pm 1.49 \mathrm{c}$ \\
$\delta-\mathrm{T} 3$ & $14.66 \pm 1.02 \mathrm{a}$ & $17.29 \pm 0.48 \mathrm{~b}$ & $18.48 \pm 0.59 \mathrm{bc}$ & $20.44 \pm 1.19 \mathrm{~d}$ & $19.28 \pm 0.23 \mathrm{~cd}$ \\
Total & $1973 \pm 41 \mathrm{a}$ & $2878 \pm 2 \mathrm{~cd}$ & $2692 \pm 63 \mathrm{~b}$ & $2820 \pm 115 \mathrm{bc}$ & $2976 \pm 119 \mathrm{~d}$ \\
\hline
\end{tabular}

Means in the same column with different letters are significantly different $(p<0.05) ; \alpha-\mathrm{T}, \alpha-\mathrm{T} 3, \beta-\mathrm{T}, \gamma-\mathrm{T}$, $\gamma$-T3, $\delta$-T, $\delta$-T3 mean $\alpha$-tocopherol, $\alpha$-tocotrienol, $\beta$-tocopherol, $\gamma$-tocopherol, $\gamma$-tocotrienol, $\delta$-tocopherol, and $\delta$-tocotrienol, sequentially.

\subsection{Composition and Content of Carotenoids in Cakes}

The composition and content of carotenoids detected in cakes are shown in Table 6. Only lutein, zeaxanthin, $\alpha-, \beta$-cryptoxanthin, and $\beta$-carotene were detected in the control, and the total content was low. Lutein, zeaxanthin, $\alpha-, \beta$-cryptoxanthin, and $\alpha-, \beta-, \varepsilon_{-}^{-,}(6 \mathrm{R})-\delta$-carotene were all detected in SCRC. Lutein, zeaxanthin, and $\alpha$-cryptoxanthin were the three most abundant carotenoids detected, which were consistent with the composition of sweet corn carotenoids. Comparing the results, we observed that the highest carotenoid content of SCRC was 3.5 times that of the control. The carotenoid content in cake was positively correlated with SCR content.

Table 6. Composition and content of carotenoids in cakes.

\begin{tabular}{cccccc}
\hline Compositions & Control & SCRC1 & SCRC2 & SCRC3 & SCRC4 \\
\hline Lut & $12.68 \pm 0.55 \mathrm{a}$ & $31.37 \pm 1.29 \mathrm{~b}$ & $51.54 \pm 2.64 \mathrm{c}$ & $69.31 \pm 4.04 \mathrm{e}$ & $64.32 \pm 2.73 \mathrm{c}$ \\
Zea & $14.05 \pm 0.77 \mathrm{a}$ & $20.14 \pm 0.24 \mathrm{~b}$ & $26.14 \pm 1.03 \mathrm{c}$ & $31.73 \pm 1.81 \mathrm{~d}$ & $31.16 \pm 3.08 \mathrm{~d}$ \\
$\alpha$-Cry & $3.28 \pm 0.10 \mathrm{a}$ & $10.33 \pm 0.05 \mathrm{~b}$ & $15.69 \pm 0.28 \mathrm{c}$ & $20.68 \pm 1.02 \mathrm{~d}$ & $19.63 \pm 0.56 \mathrm{c}$ \\
$\beta$-Cry & $13.38 \pm 1.38 \mathrm{~d}$ & $7.74 \pm 0.36 \mathrm{a}$ & $9.67 \pm 0.11 \mathrm{~b}$ & $11.58 \pm 0.18 \mathrm{c}$ & $10.44 \pm 0.71 \mathrm{bc}$ \\
$\varepsilon$-Car & ND & $6.67 \pm 0.09 \mathrm{a}$ & $8.00 \pm 0.24 \mathrm{~b}$ & $8.89 \pm 0.37 \mathrm{c}$ & $8.37 \pm 0.18 \mathrm{~b}$ \\
$\alpha$-Car & ND & $3.45 \pm 0.23 \mathrm{a}$ & $4.65 \pm 0.24 \mathrm{~b}$ & $5.72 \pm 0.67 \mathrm{c}$ & $5.34 \pm 0.34 \mathrm{bc}$ \\
$\beta$-Car & $2.35 \pm 0.02 \mathrm{~d}$ & $3.14 \pm 0.02 \mathrm{a}$ & $3.95 \pm 0.20 \mathrm{~b}$ & $4.91 \pm 0.20 \mathrm{c}$ & $4.59 \pm 0.10 \mathrm{bc}$ \\
(6R)- $\delta$-Car & ND & $3.66 \pm 0.01 \mathrm{a}$ & $5.38 \pm 0.05 \mathrm{~b}$ & $6.35 \pm 0.15 \mathrm{c}$ & $6.14 \pm 0.23 \mathrm{c}$ \\
Total $\mu \mathrm{g} / 100 \mathrm{~g}$ & $45.74 \pm 2.11 \mathrm{a}$ & $86.50 \pm 1.24 \mathrm{~b}$ & $125.0 \pm 4.6 \mathrm{c}$ & $159.2 \pm 8.1 \mathrm{e}$ & $145.0 \pm 7.9 \mathrm{~d}$
\end{tabular}

Means in the same column with different letters are significantly different $(p<0.05)$. ND means "not detected"; Lut, Zea, $\alpha$-Cry, $\beta$-Cry, $\varepsilon$-Car, $\alpha$-Car, $\beta$-Car, (6R)- $\delta$-Car, and $\gamma$-Car mean lutein, zeaxanthin, $\alpha$-cryptoxanthin, $\beta$-cryptoxanthin, $\varepsilon$-carotene, $\alpha$-carotene, $\beta$-carotene, $(6 \mathrm{R})$ - $\delta$-carotene, and $\gamma$-carotene, sequentially.

\subsection{Folate Content in Cakes}

The content of folate detected in cakes is shown in Figure 2. As shown, the folate content of SCRC increased significantly with the growth of SCR. The folate content of the SCRC4 reached 776.6 $\mu \mathrm{g} / 100 \mathrm{~g}$, which was 1.7 times that of the control. 


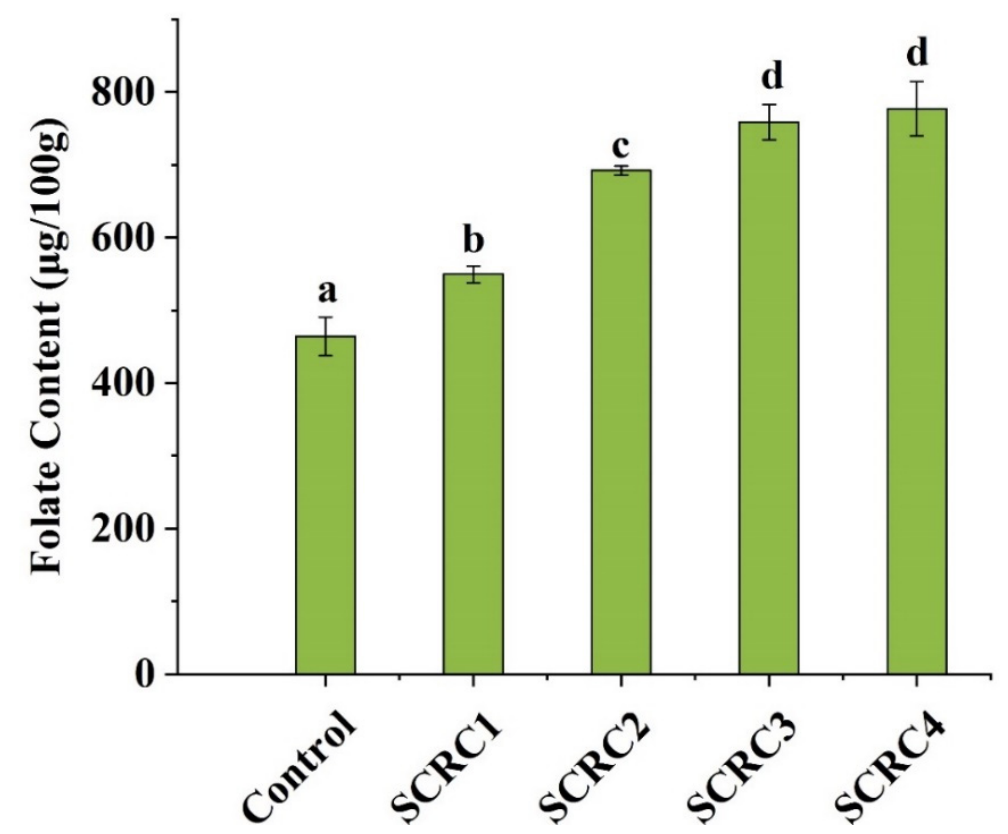

Figure 2. Content of folate in cakes with SRC addition. Bars with different letters in each fraction are significantly different $(p<0.05)$.

\subsection{Correlation between SCR Addition and Detection Indicators}

As shown in Table 7, the addition of SCR was negatively correlated with sensory scores, resilience and cohesion, but had no significant effect on other texture indexes. In addition, the correlation coefficient between dietary fiber content and SCR addition was 1, which indicated that the increase of dietary fiber in cakes was mainly due to SCR. The GI value of the cake was significantly reduced by dietary fiber brought in by SCR.

Through Table 8, there was a positive correlation between SCR addition and vitamin E content. The more SCR that was added, the more carotenoids were in cakes, and the majority of its components also showed this pattern. Folate content in cakes increased linearly with the increase of SCR. 
Table 7. Correlation between SCR addition and texture, sensory evaluation and digestibility.

\begin{tabular}{|c|c|c|c|c|c|c|c|c|c|c|c|}
\hline & Addition & Hardness & Resilience & Cohesion & Springiness & Gumminess & Chewiness & $\begin{array}{c}\text { Sensory } \\
\text { Scores }\end{array}$ & $\begin{array}{l}\text { Total } \\
\text { Sugar }\end{array}$ & Fiber & AUC \\
\hline Addition & 1.000 & & & & & & & & & & \\
\hline Hardness & 0.719 & 1.000 & & & & & & & & & \\
\hline Resilience & -0.807 & $-0.986^{* *}$ & 1.000 & & & & & & & & \\
\hline Cohesion & -0.856 & -0.950 * & $0.989 * *$ & 1.000 & & & & & & & \\
\hline Springiness & -0.676 & -0.847 & 0.871 & 0.867 & 1.000 & & & & & & \\
\hline Gumminess & 0.655 & $0.996^{* *}$ & $-0.970 * *$ & $-0.925 *$ & -0.845 & 1.000 & & & & & \\
\hline Chewiness & 0.599 & $0.978^{* *}$ & $-0.940 *$ & $-0.890 *$ & -0.741 & $0.984^{* *}$ & 1.000 & & & & \\
\hline Total sugar & 0.122 & 0.222 & -0.190 & -0.172 & 0.309 & 0.207 & 0.368 & -0.456 & 1.000 & & \\
\hline Fiber & $1.000^{* *}$ & 0.717 & -0.805 & -0.854 & -0.681 & 0.652 & 0.594 & -0.872 & 0.106 & 1.000 & \\
\hline AUC & $-0.993^{* *}$ & -0.707 & 0.800 & 0.855 & 0.626 & -0.641 & -0.602 & 0.911 * & -0.213 & $-0.991^{* *}$ & 1.000 \\
\hline
\end{tabular}

** means significant correlation at 0.01 level, * means significant correlation at 0.05 level; AUC means area under the curve, which meant total release of reduced sugar during 180 min of in vitro digestion. 
Table 8. Correlation between SCR addition and detected micronutrient components.

\begin{tabular}{|c|c|c|c|c|c|c|c|c|c|c|c|c|c|c|c|c|c|c|c|}
\hline & Addition & $\alpha-\mathrm{T}$ & $\alpha$-T3 & $\beta \mathrm{T}$ & $\gamma \mathrm{T}$ & $\gamma \mathrm{T} 3$ & $\delta \mathrm{T}$ & ¿T3 & $\begin{array}{c}\text { Total } \\
\text { VE }\end{array}$ & Lut & Zea & $\alpha$-Cry & $\beta$-Cry & $\varepsilon$-Car & $\alpha$-Car & $\beta$-Car & (6R)- $\delta-C a r$ & $\begin{array}{c}\text { Total } \\
\text { Car }\end{array}$ & Folate \\
\hline Addition & 1.000 & & & & & & & & & & & & & & & & & & \\
\hline$\alpha-T$ & 0.709 & 1.000 & & & & & & & & & & & & & & & & & \\
\hline$\alpha$-T3 & 0.981 ** & 0.813 & 1.000 & & & & & & & & & & & & & & & & \\
\hline$\beta T$ & -0.185 & 0.532 & -0.045 & 1.000 & & & & & & & & & & & & & & & \\
\hline$\gamma \mathrm{T}$ & 0.238 & 0.780 & 0.333 & 0.871 & 1.000 & & & & & & & & & & & & & & \\
\hline$\gamma \mathrm{T} 3$ & $0.987^{* *}$ & 0.800 & 0.998 ** & -0.070 & 0.326 & 1.000 & & & & & & & & & & & & & \\
\hline$\delta \mathrm{T}$ & -0.316 & -0.006 & -0.347 & 0.575 & 0.579 & -0.336 & 1.000 & & & & & & & & & & & & \\
\hline \$T3 & 0.944 * & 0.794 & $0.968^{* *}$ & -0.083 & 0.311 & 0.973 ** & -0.414 & 1.000 & & & & & & & & & & & \\
\hline Total VE & 0.782 & $0.988^{* *}$ & 0.859 & 0.457 & 0.764 & 0.851 & 0.034 & 0.831 & 1.000 & & & & & & & & & & \\
\hline Lut & $0.983^{* * *}$ & 0.724 & $0.983^{* *}$ & -0.197 & 0.206 & 0.989 ** & -0.439 & 0.982 ** & 0.778 & 1.000 & & & & & & & & & \\
\hline Zea & 0.990 ** & 0.748 & 0.990 ** & -0.158 & 0.248 & 0.995 ** & -0.393 & 0.979 ** & 0.804 & 0.998 ** & 1.000 & & & & & & & & \\
\hline$\alpha$-Cry & 0.983 ** & 0.767 & 0.991 ** & -0.133 & 0.266 & 0.995 ** & -0.403 & 0.987 ** & 0.817 & 0.998 ** & $0.999 * *$ & 1.000 & & & & & & & \\
\hline$\beta$-Cry & -0.184 & -0.814 & -0.348 & -0.898 * & -0.870 & -0.317 & -0.237 & -0.313 & -0.736 & -0.204 & -0.235 & -0.266 & 1.000 & & & & & & \\
\hline$\varepsilon$-Car & 0.912 & -0.629 & 0.936 & $-0.989 *$ & -0.797 & 0.940 & -0.622 & $0.967^{*}$ & -0.056 & $0.988^{*}$ & $0.971 *$ & $0.981 *$ & $0.994 * *$ & 1.000 & & & & & \\
\hline$\alpha-\mathrm{Car}$ & 0.952 * & -0.523 & $0.962 *$ & $-0.962 *$ & -0.716 & $0.972 *$ & -0.515 & $0.972 *$ & 0.073 & $0.999 * *$ & $0.992 * *$ & $0.997^{* *}$ & 0.991 ** & 0.992 ** & 1.000 & & & & \\
\hline$\beta$-Car & $0.981^{* *}$ & 0.697 & $0.971^{* *}$ & -0.231 & 0.187 & $0.980^{* *}$ & -0.432 & 0.981 ** & 0.757 & 0.998 ** & $0.994 * *$ & $0.993 * *$ & -0.161 & $0.982 *$ & $0.997^{* *}$ & 1.000 & & & \\
\hline (6R)- $\delta$-Car & 0.958 * & -0.546 & 0.979 * & $-0.962 *$ & -0.754 & $0.977^{*}$ & -0.543 & 0.936 & 0.042 & 0.993 ** & $0.990 *$ & $0.992 * *$ & 0.972 * & 0.987 * & $0.992 * *$ & $0.981 *$ & 1.000 & & \\
\hline Total Car & 0.980 ** & 0.736 & $0.983 * *$ & -0.181 & 0.223 & 0.988 ** & -0.435 & 0.987 ** & 0.788 & $1.000^{* *}$ & $0.998 * *$ & $0.998 * *$ & -0.220 & $0.989 *$ & 1.000 ** & $0.998^{* *}$ & $0.989 *$ & 1.000 & \\
\hline Folate & 0.991 ** & 0.692 & $0.983 * *$ & -0.224 & 0.165 & $0.985^{* *}$ & -0.432 & $0.948 *$ & 0.752 & 0.990 ** & $0.991 * *$ & $0.986 * *$ & -0.176 & $0.955^{*}$ & 0.970 * & $0.982 * *$ & $0.990 *$ & $0.985^{* *}$ & 1.000 \\
\hline
\end{tabular}

means significant correlation at 0.01 level, * means significant correlation at 0.05 level. $\alpha$-T, $\alpha$-T3, $\beta$-T, $\gamma$-T, $\gamma$-T3, $\delta$-T, $\delta$-T3 mean $\alpha$-tocopherol, $\alpha$-tocotrienol, $\beta$-tocopherol, $\gamma$-tocopherol

$\gamma$-tocotrienol, $\delta$-tocopherol and $\delta$-tocotrienol sequentially; $\mathrm{VE}$ - means vitamin $\mathrm{E}$; Lut, Zea, $\alpha$-Cryy, $\beta$-croxanthin, $\varepsilon$-carotene, $\alpha$-carotene, $\beta$-carotene, $(6 \mathrm{R})-\delta$-carotene and $\gamma$-carotene sequentially. 


\section{Discussion}

\subsection{The Relationship between Sensory and Textural Characteristics}

Sensory evaluation of cake quality is based on individual judgment of evaluation criteria, which is subjective. However, it can predict consumers' acceptance and preference to an extent. Besides, the texture of cake can be predicted by the amount of eggs, milk, grease, flour, and other ingredients, and then it depends on the processing conditions, such as batter mixing and baking temperature and methods.

Singh et al. [26] indicated that cake with corn bran had a low taste score, but the substitution level of $10 \%$ and $20 \%$ had no significant effect on the overall acceptability score of the cake. In our study, we found that the cake became harder and stickier with springiness and resilience decreasing significantly when the SCR content reached $90 \%$ or $100 \%$. Correspondingly, the scores of taste and texture in sensory evaluation decreased. Also, the sensory and texture characteristics of SCR1 and SCR2 were similar to those of the control with the same scores. Our results showed that SCR could be a suitable substitute for wheat flour without significantly affecting the sensory properties and texture characteristics of cakes, such as SCRC1 and SCRC2.

\subsection{Interaction between Dietary Fiber and Digestion In Vitro}

Researchers have confirmed that the nutritional value of cakes improved by incorporating dietary fiber properly [27]. In our study, when the substitution amount of SCR reached 60\%, the dietary fiber content of SCR2 was 1.6 times that of the control, and it maintained a good taste. Additionally, dietary fiber was used to further reduce GI content in starchy foods, such as pasta [28]. Our results showed that the AUC decreased while dietary fiber increased. The growth of dietary fiber in samples mainly came from the increase of SCR, which confirmed that the addition of SCR reduced GI values. The AUC of SCRC2 was only $41 \%$ of Blank, which indicated that it was a delicious cake with slow digestibility.

However, there was no significant correlations among the measured total sugar content, dietary fiber, and AUC. The main reasons were as follows. Firstly, the total sugar determined by the anthrone method contained soluble reducing sugar and non-reducing sugar, such as dietary fiber. Our samples were rich in dietary fiber, which accounted for a large part of the total sugar content. Secondly, some studies pointed out that the combination of dietary fiber in pasta formulations showed a significant reducing sugar decrease in vitro [29]. In other words, SCR brought in abundant dietary fibers, which could antagonize the release process of reducing sugar during in vitro digestion.

Based on the results and discussion above, we rated that SCR2 was a viable and delicious cake formula with rich dietary fiber and a lower GI value, owing to the substitution of SCR.

\subsection{Micronutrient Fortification Effects in Cakes}

Many surveys revealed that people usually intake vitamin E with antioxidant activity through vegetables and fruits $[9,30]$. Moreover, studies have found that proper processing does not significantly affect vitamin E content and activity [31]. Our detected results agreed with it, which showed that all the cakes in this study contained a high content of vitamin E. The vitamin $\mathrm{E}$ in cakes mainly came from corn oil and SCR. From the results, we knew that the content of vitamin $\mathrm{E}$ increased with the addition of SCR under the premise of the same use of corn oil. The content of vitamin E in SCRC2 was 1.4 times that of the control, which meant it enhanced vitamin $\mathrm{E}$ to some extent by adding SCR.

Carotenoids are common substances in the food and health products industry. They have the characteristics of anti-oxidation, immune regulation, anti-cancer, and anti-aging [32]. Some studies have indicated that people can obtain high-content carotene by making whole wheat or corn baked food [33]. Similarly, we found that the content of carotenoids increased significantly with the increase of SCR. According to the results, there were four carotenoid components in the control but seven in SCRC. It indicated that the addition of SCR enriched the composition of carotenoids in cakes while 
improving content. Compared with the control, the increase of carotenoids was $170 \%$ in SCRC2. In other words, SCRC2 achieved high-efficiency enhancement of carotenoids and had potential as a supplement. Consumers would prefer to supplement natural carotenoids with delicious SCRC2 rather than synthetic tablets.

Researchers have pointed out that folate had a small amount of loss in the process of baking and storage $[34,35]$. Similarly, SCR lost parts of folate during cake baking. However, according to our results, adding SCR was still an economical and effective way to fortify folate. Folate can prevent fetal neural tube defects and is one of the indispensable nutrients for fetal growth and development [36]. The recommended daily supplement of folate for pregnant women is $400 \mu \mathrm{g}$ per day. In our study, $100 \mathrm{~g}$ of SCRC2 contained $692 \mu \mathrm{g}$ folate, which could meet this requirement within the normal consumption range. Besides, too much folic acid is a burden on the human liver, so experts suggest that biofortification should be used to increase folate content in staple foods or fruits and vegetables as a safer way to supplement folate [36]. The folate content in cakes fortified by SCR coincided with this suggestion.

\section{Conclusions}

In our study, different proportions of SCR were used instead of wheat flour to make cakes. We found that SCR could be used as an excellent carrier to fortify dietary fiber, carotenoids, vitamin E, and folate for baking foods. Through overall evaluation, SCRC2 was the best formulation with excellent food quality. Also, it had the characteristics of slow digestibility and high micronutrient content, which would be popular with consumers.

Author Contributions: Conceptualization, X.-B.G., Y.-Y.Y., and Y.-X.L.; methodology, Y.-X.L. and Y.-Y.Y.; software, X.-P.X. and W.L.; validation, S.-Y.C., Y.-X.L., and X.-M.W.; formal analysis, Y.-X.L. and X.-P.X.; investigation, S.-Y.C., Y.-Y.Y., and Y.-X.L.; resources, G.-K.L. and J.-G.H.; data curation, X.-P.X. and Y.-Y.Y.; writing-original draft preparation, Y.-X.L.; writing-review and editing, X.-B.G.; visualization, Y.-X.L. and S.-Y.C.; supervision, X.-B.G.; project administration, J.-G.H.; funding acquisition, X.-B.G. and J.-G.H.

Funding: This research was funded by Science and Technology Planning Project of Guangzhou-China, 201804020081; Science and Technology Planning Project of Guangdong Province-China, 2016B02033004 and 2017B090907023.

Acknowledgments: The authors are very thankful to the Analytical and Testing Center of SCUT for laboratory analyses.

Conflicts of Interest: The authors declare no conflict of interest. The funders had no role in the design of the study; in the collection, analyses, or interpretation of data; in the writing of the manuscript, or in the decision to publish the results.

\section{References}

1. Beilharz, J.; Maniam, J.; Morris, M. Diet-induced cognitive deficits: The role of fat and sugar, potential mechanisms and nutritional interventions. Nutrients 2015, 7, 6719-6738. [CrossRef] [PubMed]

2. Okarter, N.; Liu, R.H. Health benefits of whole grain phytochemicals. Crit. Rev. Food Sci. Nutr. 2010, 50, 193-208. [CrossRef] [PubMed]

3. Borneo, R.; León, A.E. Whole grain cereals: Functional components and health benefits. Food Funct. 2012, 3 , 110-119. [CrossRef]

4. Gómez, M.; Manchón, L.; Oliete, B.; Ruiz, E.; Caballero, P.A. Adequacy of wholegrain non-wheat flours for layer cake elaboration. LWT Food Sci. Technol. 2010, 43, 507-513. [CrossRef]

5. Žilić, S.; Kocadağlı, T.; Vančetović, J.; Gökmen, V. Effects of baking conditions and dough formulations on phenolic compound stability, antioxidant capacity and color of cookies made from anthocyanin-rich corn flour. LWT Food Sci. Technol. 2016, 65, 597-603. [CrossRef]

6. Omoba, O.S.; Taylor, J.R.N.; de Kock, H.L. Sensory and nutritive profiles of biscuits from whole grain sorghum and pearl millet plus soya flour with and without sourdough fermentation. Int. J. Food Sci. Technol. 2015, 50, 2554-2561. [CrossRef] 
7. Abdel-Aal el, S.M.; Young, J.C.; Akhtar, H.; Rabalski, I. Stability of lutein in wholegrain bakery products naturally high in lutein or fortified with free lutein. J. Agric. Food Chem. 2010, 58, 10109-10117. [CrossRef]

8. Lattimer, J.M.; Haub, M.D. Effects of dietary fiber and its components on metabolic health. Nutrients 2010, 2, 1266-1289. [CrossRef]

9. Galli, F.; Azzi, A.; Birringer, M.; Cook-Mills, J.M.; Eggersdorfer, M.; Frank, J.; Cruciani, G.; Lorkowski, S.; Ozer, N.K. Vitamin E: Emerging aspects and new directions. Free Radic. Biol. Med. 2017, 102, 16-36. [CrossRef]

10. Milani, A.; Basirnejad, M.; Shahbazi, S.; Bolhassani, A. Carotenoids: Biochemistry, pharmacology and treatment. Br. J. Pharmacol. 2017, 174, 1290-1324. [CrossRef]

11. Rao, A.V.; Rao, L.G. Carotenoids and human health. Pharmacol. Res. 2007, 55, 207-216. [CrossRef] [PubMed]

12. McNulty, H.; Pentieva, K.; Hoey, L.; Strain, J.; Ward, M. Nutrition throughout life: Folate. Int. J. Vitam. Nutr. Res. 2012, 82, 348-354. [CrossRef] [PubMed]

13. Stamm, R.; Houghton, L. Nutrient intake values for folate during pregnancy and lactation vary widely around the world. Nutrients 2013, 5, 3920-3947. [CrossRef]

14. Na, X.; Guohua, H. Effects of xanthan gum and corn flour on the quality of sponge cake using response surface methodology. Czech J. Food Sci. 2018, 36, 344-351. [CrossRef]

15. ISO 8587:2006. Sensory Analysis-Methodology-Ranking; Iso International Standard: Geneva, Switzerland, 2006.

16. ISO 5495:2005. Sensory Analysis. Methodology. Paired Comparison Test; Iso International Standard: Geneva, Switzerland, 2005.

17. Brites, C.; Trigo, M.J.; Santos, C.; Collar, C.; Rosell, C.M. Maize-Based Gluten-Free Bread: Influence of Processing Parameters on Sensory and Instrumental Quality. Food Bioprocess Technol. 2008, 3, 707-715. [CrossRef]

18. Haldar, D.; Sen, D.; Gayen, K. Development of spectrophotometric method for the analysis of multi-component carbohydrate mixture of different moieties. Appl. Biochem. Biotechnol. 2017, 181, 1416-1434. [CrossRef] [PubMed]

19. Kamotho, S.; Kyallo, F.; Sila, D. Biofortification of maize flour with grain amaranth for improved nutrition. Afr. J. Food Agric. Nutr. Dev. 2017, 17, 12574-12588. [CrossRef]

20. Gao, J.; Brennan, M.A.; Mason, S.L.; Brennan, C.S. Effect of sugar replacement with stevianna and inulin on the texture and predictive glycaemic response of muffins. Int. J. Food Sci. Technol. 2016, 51, 1979-1987. [CrossRef]

21. Goñi, I.; Garcia-Alonso, A.; Saura-Calixto, F. A starch hydrolysis procedure to estimate glycemic index. Nutr. Res. 1997, 17, 427-437. [CrossRef]

22. Xie, L.; Yu, Y.; Mao, J.; Liu, H.; Hu, J.G.; Li, T.; Guo, X.; Liu, R.H. Evaluation of Biosynthesis, Accumulation and Antioxidant Activityof Vitamin E in Sweet Corn (Zea mays L.) during Kernel Development. Int. J. Mol. Sci. 2017, 18, 2780. [CrossRef] [PubMed]

23. Liu, F.; Xiang, N.; Hu, J.G.; Shijuan, Y.; Xie, L.; Brennan, C.S.; Huang, W.; Guo, X. The manipulation of gene expression and the biosynthesis of Vitamin C, E and folate in light-and dark-germination of sweet corn seeds. Sci. Rep. 2017, 7, 7484. [CrossRef] [PubMed]

24. Liu, H.; Mao, J.; Yan, S.; Yu, Y.; Xie, L.; Hu, J.G.; Li, T.; Abbasi, A.M.; Guo, X.; Liu, R.H. Evaluation of carotenoid biosynthesis, accumulation and antioxidant activities in sweetcorn (Zea mays L.) during kernel development. Int. J. Food Sci. Technol. 2018, 53, 381-388. [CrossRef]

25. Shan, Q.-J.; Liu, J.-H.; Li, W.; Wang, H.; Hu, X.-D.; Li, T.; Hu, J.-G.; Guo, X.-B.; Liu, R.H. Comprehensive evaluation of biosynthesis, accumulation, regulation of folate and vitamin $\mathrm{C}$ in waxy maize (Zea mays L. var. ceratina) with kernel development. J. Cereal Sci. 2019, 87, 215-224. [CrossRef]

26. Singh, M.; Liu, S.X.; Vaughn, S.F. Effect of corn bran as dietary fiber addition on baking and sensory quality. Biocatal. Agric. Biotechnol. 2012, 1, 348-352. [CrossRef]

27. Lebesi, D.M.; Tzia, C. Effect of the Addition of Different Dietary Fiber and Edible Cereal Bran Sources on the Baking and Sensory Characteristics of Cupcakes. Food Bioprocess Technol. 2009, 4, 710-722. [CrossRef]

28. Foschia, M.; Peressini, D.; Sensidoni, A.; Brennan, C.S. The effects of dietary fibre addition on the quality of common cereal products. J. Cereal Sci. 2013, 58, 216-227. [CrossRef]

29. Foschia, M.; Peressini, D.; Sensidoni, A.; Brennan, M.A.; Brennan, C.S. Synergistic effect of different dietary fibres in pasta on in vitro starch digestion? Food Chem. 2015, 172, 245-250. [CrossRef]

30. Slavin, J.L.; Lloyd, B. Health benefits of fruits and vegetables. Adv. Nutr. 2012, 3, 506-516. [CrossRef] 
31. Dewanto, V.; Wu, X.; Liu, R.H. Processed sweet corn has higher antioxidant activity. J. Agric. Food Chem. 2002, 50, 4959-4964. [CrossRef]

32. Irwandi, J. Carotenoids: Sources, medicinal properties and their application in food and nutraceutical industry. J. Med. Plants Res. 2011, 5, 7119-7131. [CrossRef]

33. Abdel-Aal el, S.M.; Akhtar, H.; Zaheer, K.; Ali, R. Dietary sources of lutein and zeaxanthin carotenoids and their role in eye health. Nutrients 2013, 5, 1169-1185. [CrossRef] [PubMed]

34. Phillips, R.; Pike, O.A.; Eggett, D.L.; Dunn, M.L. Folate Stability in Folic Acid Enriched Corn Masa Flour, Tortillas, and Tortilla Chips over the Expected Shelf Life. Cereal Chem. 2017, 94, 917-921. [CrossRef]

35. Burton, K.; Steele, F.M.; Jefferies, L.; Pike, O.A.; Dunn, M.L. Effect of micronutrient fortification on nutritional and other properties of nixtamal tortillas. Cereal Chem. 2008, 85, 70-75. [CrossRef]

36. Eichholzer, M.; Tönz, O.; Zimmermann, R. Folic acid: A public-health challenge. Lancet 2006, 367, $1352-1361$. [CrossRef]

(C) 2019 by the authors. Licensee MDPI, Basel, Switzerland. This article is an open access article distributed under the terms and conditions of the Creative Commons Attribution (CC BY) license (http://creativecommons.org/licenses/by/4.0/). 